\title{
Strategi Komunikasi Pemasaran Dalam Meningkatkan Jumlah Penginap Di Hotel Best Skip Palembang
}

\author{
Hambali, Gita Astrid, Yustika Utari \\ Fakultas Ilmu Sosial dan Ilmu Politik Universitas Islam Negeri Raden Fatah \\ Email: utariyustika@gmail.com
}

\begin{abstract}
This study aims to determine the marketing strategy carried out by the Best Skip Hotel in increasing the number of residents. Best Skip Hotel is a 2 star Hotel located in the center of Palembang. Best Skip Hotel has complete facilities with cheap and affordable tariffs for all people. The methods used in this research is to use descriptive qualitative methods, data collection techniques conducted by researchers through interviews, documentation, and observation. Primary data sources in this study are the General Manager, Marketing Team, Hotel visitors, and Hotel staff and employees. While the secondary data source is in the form of documents, organizational structure, and books related to research. The Hotel implements several communication models such as direct and indirect communication. Direct communication conducted by this Hotel is in the form of Sales Promotion, Personal Selling, and Direct Selling. While the indirect communication made by this Hotel is by using promotions through social media such as Facebook, Tweeter, Instagram, the internet, brochures, and so on. The Best Skip Palembang Hotel adopts a strategy that is more focused on promotional activities, but the Hotel also strives to maximize the quality of its products, facilities, price, and services in order to meet customer needs. Marketing promotion activities carried out by Marketing at the Best Skip Hotel are through promotional banners and internet promotions, because these promotional activities cost relatively cheaply but can have maximum results. The internal activities of the Hotel every day hold daily meetings to monitor how the development and condition of the Hotel. The next strategic process is by analyzing the situation by Marketing and Hotel Managers such as conducting research by analyzing Income Audit reports or daily income in the form of finances and the number of guests staying. In addition, the Marketing also monitors customer feedback or responses through customer comments on the Hotel Website. Factors that influence the stay at the Best Skip Hotel is because this Hotel has a cheap price and fairly complete facilities.
\end{abstract}

Keywords: communication strategy, marketing,visitors, hotel

\begin{abstract}
Abstrak
Penelitian ini bertujuan untuk mengetahui strategi pemasaran yang dilakukan oleh Hotel Best Skip Palembang dalam meningkatkan jumlah penginapnya. Hotel Best Skip merupakan Hotel bintang 2
\end{abstract}


yang terletak di pusat kota Palembang. Hotel Best Skip memiliki fasilitas yang cukup lengkap dengan daya tarif yang murah dan terjangkau bagi semua kalangan masyarakat. Metode penelitian yang dilakukan dalam penelitian ini yaitu menggunakan metode deskriptif kualitatif, teknik pengumpulan data yang dilakukan peneliti yaitu melalui wawancara, dokumentasi, dan observasi. Sumber data informan dalam penelitian ini yaitu General Manager, Team Marketing, pengunjung Hotel, serta staff dan karyawan di Hotel Best Skip. Selain itu diperkuat dengan menggunakan data berupa dokumen, struktur organisasi, serta buku yang menjadi referensi penelitian. Hotel ini menerapkan beberapa model komunikasi seperti komunikasi langsung dan tidak langsung. Komunikasi langsung yang dilakukan Hotel ini yaitu berupa Sales Promotion, Personal Selling, dan Direct Selling. Sedangkan komunikasi tidak langsung yang dilakukan Hotel ini yaitu dengan menggunakan promosi melalui media sosial seperti facebook, tweeter, instagram, internet, brosur, dan lain sebagainya. Hotel Best Skip Palembang menerapkan strategi yang lebih fokus kepada promosi, namun Hotel ini juga berusaha untuk memaksimalkan kualitas produk, fasilitas, harga, dan pelayanannya guna untuk memenuhi kebutuhan pelanggan. Kegiatan promosi pemasaran yang dilakukan oleh Marketing di Hotel Best Skip yaitu melalui spanduk promosi maupun promosi internet, dikarenakan kegiatan promosi ini memakan biaya yang relatif murah namun dapat memiliki hasil yang maksimal. Kegiatan internal Hotel setiap hari mengadakan meeting harian untuk memantau bagaimana perkembangan dan kondisi Hotel. Proses strategi yang selajutnya yaitu dengan melakukan analisis situasi oleh Marketing dan Manager Hotel seperti mengadakan riset dengan menganalisa laporan Income Audit atau pendapatan setiap harinya baik berupa keuangan maupun jumlah tamu yang menginap. Selain itu, pihak Marketing juga memantau feedback atau respon pelanggan melalui komentar pelanggan pada website Hotel. Faktor yang mempengaruhi penginap di Hotel Best Skip yaitu karena Hotel ini memiliki harga yang murah dan fasilitas yang cukup lengkap.

Kata Kunci: strategi komunikasi, marketing, pengunjung, hotel

\section{PENDAHULUAN}

Komunikasi mempunyai peranan penting didalam perusahaan, khususnya di bidang pemasaran. Komunikasi yang tidak baik didalam perusahaan dapat merusak citra peerusahaan terhadap loyalitas pelanggan, dan akan menimbulkan kerugian pada perusahaan. Sebaliknya, komunikasi yang efektif akan menimbulkan hubungan baik dengan banyak pihak, dan kemudian akan mendatangkan keuntungan bagi perusahaan (Wijayanto, 2013).

Semakin tinggi persaingan yang terjadi di dunia perhotelan khususnya di kota Palembang, maka Hotel juga ditekankan untuk dapat terus memajukan dan meningkatkan jumlah konsumennya agar pihak Hotel mampu mendapatkan keuntungan sesuai dengan strategi yang dilakukannya. Hal ini juga terjadi pada salah satu Hotel di Palembang yakni Hotel Best Skip.

Hotel Best Skip merupakan salah satu Hotel bintang dua yang terletak di pusat kota Palembang. Hotel Best Skip mempunyai komitmen untuk memastikan penginapan pelanggan senyaman mungkin, melayani konsumen dengan sebaik mungkin yang disertai dengan berbagai macam faslitas dan harga yang terjangkau bagi semua kalangan masyarakat yakni sekitar Rp.300.000- Rp.500.000 (harga normal). Beberapa fasilitas yang terdapat di Hotel ini seperti parkir 
gratis, sarapan gratis, Spa, Wifi gratis, Loundry 24 jam, ruang rapat, ruang pertemuan, dan lain sebagainya. Hal ini menjadikan Hotel Best Skip banyak diminati pengunjung baik pada hari biasa ataupun di akhir pekan.

Hotel Best Skip Palembang berada ditempat yang strategis untuk menikmati obyek wisata dan aktivitas dikota Palembang, Hotel ini hanya berjarak $10 \mathrm{~km}$ dari bandara SMB II Palembang. Selain itu, Hotel ini mempunyai beberapa media sosial seperti facebook, instagram, twitter, email dan lain sebagainya yang memudahkan pengunjung untuk mendapatkan berbagai informasi seputar Hotel Best Skip Palembang.

Setiap Hotel tentu mempunyai strategi tersendiri untuk meningkatkan jumlah pelanggannya. Persaingan Hotel di Palembang setiap tahunnya semakin menjamur sehingga pihak Hotel harus siap untuk bersaing, mulai dari meningkatkan kualitas produknya, fasilitas, harga, maupun strategi nya dalam mempromosikan barang atau jasa kepada konsumen agar dapat menarik minat konsumen.

Berdasarkan hal tersebut, pihak Marketing Hotel harus mempunyai beberapa strategi yang efektif untuk mendapatkan dan menarik pelanggan ataupun konsumen nya. Diantaranya yaitu dengan menjaga hubungan yang baik antara Marketing dengan berbagai pihak luar agar dapat mempertahankan dan memperkuat loyalitasnya didalam dunia bisnis perhotelan, salah satunya yaitu dengan melakukan strategi pemasaran dengan tepat dan benar.

Salah satu Hotel yang bergerak dibidang pemasaran ini yaitu Hotel Best Skip Palembang. Bagi Hotel Best Skip sendiri, pihak Marketing harus fokus dalam meningkatkan jumlah penginap atau konsumen di Hotel. Oleh karena itu, penulis tertarik untuk mengangkat permasalahan tersebut dengan judul "Strategi Komunikasi Pemasaran dalam Meningkatkan Jumlah Penginap di Hotel Best Skip Palembang”.

\section{METODE PENELITIAN}

Metode penelitian dalam penelitian ini yaitu menggunakan medote deskriptif kualitatif, yakni peneliti menggambarkan serta menguraikan data yang diperoleh dari hasil penelitian kemudian ditarik kesimpulannya untuk mengetahui strategi komunikasi pemasaran yang ada di Hotel Best Skip Palembang. Peneliti melakukan penelitian dengan menggunakan teknik wawancara, yang melibatkan beberapa sumber internal yakni General Manager, Team Marketing, pengunjung Hotel, serta staff dan karyawan yang ada di Hotel Best Skip Palembang. Selain itu, sumber data pendukung pada penelitian ini yaitu melalui dokumentasi, buku yang menjadi referensi dalam penelitian, serta internet. Penelitian ini menggunakan teori Marketing Mix, yakni terdapat 9 elemen seperti Product, Price, Place, Promotion, People, Physical Evidence, Process, Packaging, dan Payment.

\section{HASIL DAN PEMBAHASAN}

Berdasarkan hasil wawancara yang sudah di deskripsikan oleh peneliti untuk menjawab rumusan masalah yang telah ditentukan, peneliti juga memberikan penjelasan secara mendalam bagaimana 
hasil dari strategi komunikasi pemasaran di Hotel Best Skip Palembang, maka peneliti melakukan penelitian dengan menggunakan teknik wawancara yang melibatkan beberapa sumber internal yakni General Manager, Team Marketing, pengunjung Hotel, serta staff dan pegawai di Hotel Best Skip Palembang. Beberapa hasil penelitian tersebut dapat diperjelas sebagai berikut:

\section{Komunikasi Pemasaran}

Proses komunikasi pemasaran yang diterapkan oleh Hotel ini yaitu melalui komunikasi secara langsung dan tidak langsung. Komunikasi langsung yang dilakukan oleh Hotel ini yaitu berupa Sales Promotion, Personal Selling, dan Direct Selling. Seperti yang diungkapkan oleh Dinda :

"Dalam pemasarannya kita lebih banyak menggunakan promosi sebagai sarana untuk penjualan, salah satunya yaitu dengan melakukan penjualan langsung. Penjualan langsung disini artinya kita harus bisa meyakinkan pelanggannya secara langsung, agar mereka tertarik dengan apa yang kita tawarkan"

Pernyataan tersebut dapat diartikan bahwa komunikasi pemasaran selalu berkaitan dengan promosi, dikarenakan promosi mempunyai peran yang sangat penting dalam melakukan kegiatan pemasarannya. Kegiatan pemasaran Hotel tidak hanya fokus pada kepuasan konsumen saja, akan tetapi Hotel harus mampu menciptakan keunikannya tersendiri untuk membedakan antara Hotel Best Skip dengan yang lainnya.

Selain itu, komunikasi tidak langsung yang digunakan oleh Hotel ini yaitu promosi melalui media sosial seperti instagram, facebook, tweeter, dan promosi melalui brosur. Berdasarkan hasil penelitian ini peneliti juga menemukan data dari hasil wawancara seperti yang diungkapkan oleh Dinda :

"Untuk promosi kita juga menggunakan media sosial seperti instagram, facebook, tweeter, kemudian menggunakan brosur dan lain sebagainya".

Strategi komunikasi pemasaran merupakan suatu perencanaan yang digunakan untuk mencapai tujuan yang telah dibuat sesuai dengan visi dan misi perusahaan. Saat ini banyak perusahaan yang dihadapkan dengan berbagai macam persaingan bisnis yang semakin meningkat, oleh karena itu strategi pemasaran dibidang usaha menjadi sangat penting untuk mendapatkan keuntungan dalam setiap proses pemasaran yang dilakukan (Morisson, 2010).

Media sosial saat ini tidak hanya dijadikan tempat hiburan saja, akan tetapi melalui media sosial ini suatu Hotel dapat menjadikannya sebagai alat atau sarana untuk mempromosikan produk atau jasa nya, sehingga konsumen dapat lebih mudah menemukan berbagai informasi mengenai Hotel tersebut. Selain itu, pihak Hotel juga akan mendapatkan keuntungan yang maksimal jika usaha nya dapat diminati oleh banyak konsumen. 
Berdasarkan uraian diatas Hotel ini menggunakan beberapa teknik komunikasi pemasaran secara langsung dan tidak langsung dalam melakukan promosi penjualannya, selain itu peneliti juga menemukan beberapa dokumentasi dari Hotel tersebut yang dapat dilihat pada gambar berikut :

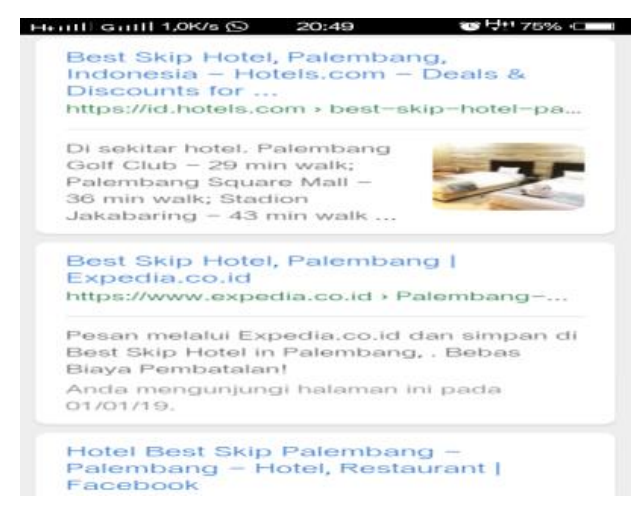

Gambar diatas adalah website dari Hotel Best Skip Palembang yang biasanya digunakan untuk menyampaikan berbagai macam promosi mengenai produk, harga, jenis kamar, serta informasi lainnya yang dapat memudahkan konsumen untuk mendapatkan beberapa informasi mengenai Hotel sesuai dengan yang dibutuhkan oleh konsumen. Selain itu media promosi yang digunakan oleh Hotel ini yaitu melalui Instagram yang dapat dilihat pada gambar berikut :

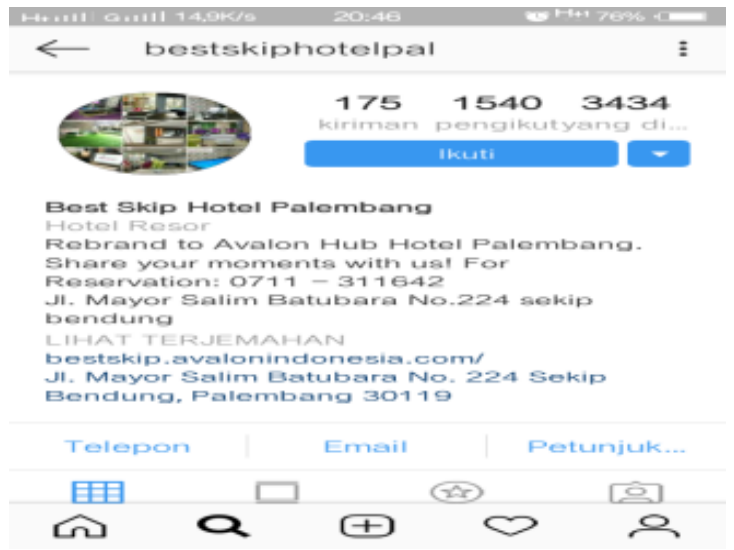

Setiap pengusaha tentu memiliki keinginan agar perusahaan yang dimiliki banyak diminati oleh konsumen ataupun pengunjung, begitu juga di dunia perhotelan. Salah satu strategi promosi yang dilakukan Hotel ini yaitu melalui media Instagram. Instagram merupakan media sosial yang sangat efektif dalam dunia bisnis karena dapat menjangkau ke lebih banyak orang, sehingga sebuah produk atau jasa akan meningkat sesuai dengan yang diharapkan oleh suatu perusahaan.

Jika kita lihat dan tinjau lebih dalam, instagram bukan hanya sebuah penyampaian informasi atau untuk hiburan tetapi media instagram menjadi salah satu peluang bisnis yakni 
memasarkan produk, membuat iklan, sehingga para konsumen atau pengguna smartphone dapat dengan mudah mendapatkan info yang ingin didapatkan, hal inilah yang dilihat dari Hotel Best Skip Palembang.

Selanjutnya Hotel ini juga menggunakan media sosial seperti Facebook dalam melakukan promosi nya, yang dapat dilihat pada gambar berikut :

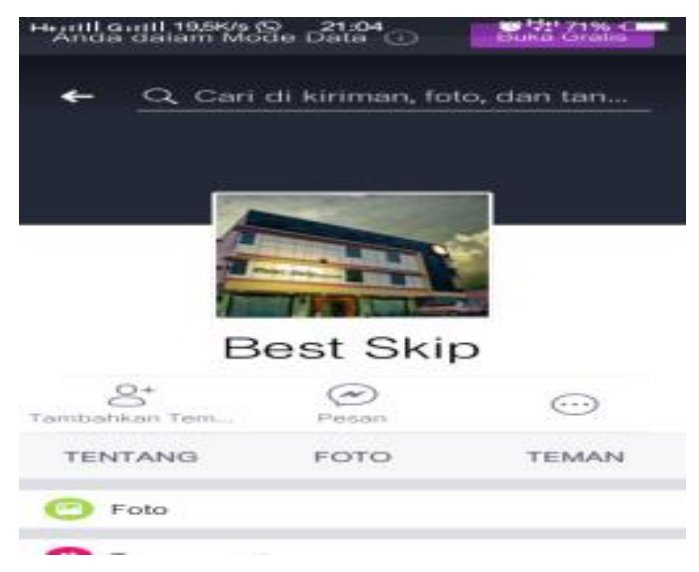

Selain itu, Hotel Best Skip ini juga menggunakan media promosi melalui facebook. Melalui facebook maka proses pemasaran yang dilakukan akan terjangkau dengan sangat luas, dikarenakan pengguna facebook ini banyak sekali yang menggunakannya mulai dari kalangan remaja, anakanak, pelajar, maupun orang tua. Sehingga, ketika melakukan kegiatan promosi nya maka akan banyak sekali yang melihat informasi tersebut dan akan berdampak pada meningkatnya jumlah pelanggan atau konsumen nya.

Kemudian, Hotel ini juga menggunakan brosur dalam melakukan promosi nya. Berikut contoh brosur yang dimiliki oleh Hotel Best Skip :

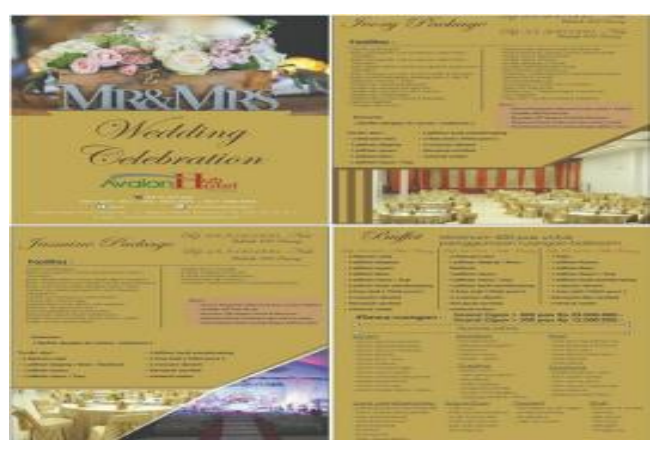

Hotel ini juga menggunakan media brosur dalam melakukan kegiatan pemasarannya. Brosur dapat dikatakan cukup efektif untuk menyebarkan promosi kepada konsumen, melalui brosur ini maka konsumen akan lebih mudah mendapatkan informasi mengenai Hotel Best Skip, 
mulai dari harga, produk, tempat, dan lain sebagainya. Melalui brosur ini juga konsumen bisa menghubungi nomor telepon yang tertera pada brosur jika dibutuhkan.

Kegiatan promosi pemasaran yang dilakukan oleh Hotel Best Skip Palembang yaitu melalui spanduk promosi maupun internet, dikarenakan kegiatan promosi ini memakan biaya yang cukup murah akan tetapi dapat memiliki hasil yang maksimal. Kegiatan internal Hotel Best Skip setiap hari selalu mengadakan meeting harian untuk melihat bagaimana perkembangan dan kondisi Hotel. Strategi komunikasi pemasaran yang dilakukan oleh Hotel ini yaitu tidak hanya penjualan kamar saja, seperti yang diungkapkan oleh Dinda :

“Jadi strateginya selain penjualan kamar, kita jualnya lebih ke event juga. Pemasarannya ditujukan juga untuk meeting, wedding, perkantoran, dan untuk penjualan kamar bisa dipesan melalui traveloka dan website Hotel"

Keberhasilan promosi disuatu Hotel biasanya ditentukan oleh bagaimana cara melakukan pengawasan terhadap kebutuhan konsumen atau pelanggan yang diharapkan datang sesuai dengan yang diharapkan perusahaan. Oleh karena itu, manajer pemasaran dituntut untuk selalu mencari strategi pemasaran yang benar agar mampu bersaing dalam kondisi apapun, sehingga perusahaan dapat mempengaruhi konsumen untuk menggunakan jasa perusahaan (Budi, 2013).

\section{Strategi Komunikasi Pemasaran}

Hotel Best Skip Palembang menerapkan strategi yang lebih fokus kepada kegiatan promosi, namun Hotel ini juga berusaha untuk memaksimalkan kualitas produk, fasilitas, harga, dan pelayanannya agar dapat memenuhi kebutuhan konsumen. Selain itu, peneliti juga menemukan data seperti yang diungkapkan oleh Elly. S, bahwa :

"Seiring berkembangnya zaman, tentunya kita harus menciptakan ide-ide atau perkembangan baru seperti produk, kemudian konsep yang lama diganti ke konsep yang baru dan itu harus diperbarui secara terus menerus".

Maksud dari pernyataan diatas adalah produk didalam suatu perusahaan harus ada perkembangan sesuai dengan semakin berkembangnya zaman, karena produk atau jasa ini merupakan sesuatu yang bisa ditawarkan kepada pelanggan atau konsumen guna untuk menarik minat konsumen dalam menggunakan jasa yang diberikan sehingga dapat memenuhi kebutuhannya.

Proses strategi selanjutnya yang dilakukan oleh Hotel Best Skip selanjutnya yakni melakukan analisis situasi oleh Marketing dan Manager Hotel Best Skip dengan mengadakan riset seperti menganalisa laporan Income Audit atau pendapatan setiap harinya baik berupa keuangan maupun jumlah tamu yang menginap. Selain itu pihak Marketing juga memantau feedback atau respon pelanggan melalui komentar pelanggan pada website Hotel. Berdasarkan komentar pelanggan melalui website tersebut, peneliti juga menemukan data komentar pelanggan seperti yang diungkapkan oleh Lesta Minarni bahwa : 
"Hotel ini nyaman, kamarnya nyaman, dan gedung pernikahannya juga nyaman dan luas, soal harga sesuai sama kantong kita, kalau mau pake gedung nikah disini hitungannya perundangan jadi bisa disesuaikan dengan biaya yang ada dan tamu yang akan diundang, dan pelayanannya juga sangat bagus”.

Berdasarkan respon pelanggan diatas dapat dilihat bahwa respon yang diberikan oleh pelanggan menunjukkan nilai yang positif kepada Hotel mulai dari harga, pelayanan, serta fasilitas yang diberikan oleh Hotel dapat memnuhi kebutuhan konsumen. Selain itu, pelayanan yang diberikan Hotel ini lebih mengutamakan kenyamanan konsumen seperti yang dijelaskan oleh Wilza

"Kita lebih mengutamakan kenyamanan pelanggan senyaman mungkin, karena kalau kita tidak membuat pelanggan nyaman sama seperti kita tidak menghargai pelanggannya".

Proses pemasaran selanjutnya yang dilakukan oleh Hotel ini yaitu penetapan harga. Harga dari suatu produk atau jasa menjadi sangat penting dan merupakan strategi pemasaran yang dapat mempengaruhi keberhasilan suatu perusahaan untuk mendapatkan keuntungan. Hotel ini terbilang cukup murah seperti yang diungkapkan oleh Wilza :

"Kalau untuk harga penjualan per kamarnya yaitu Rp.300.000 untuk kamar standar dan Rp.500.000 untuk kamar familly dan itu harga normalnya”.

Selain itu, Dinda juga menyebutkan bahwa :

"Hotel Best Skip ini memiliki harga yang standar dan harga yang sangat bersahabat, namun memiliki fasilitas dan kualitas yang bagus seperti Hotel kelas atas lainnya”.

Beberapa komentar pelanggan pada website Hotel Best Skip ini menunjukkan bahwa Hotel ini memiliki harga yang cukup murah, seperti yang diungkapkan oleh Djamal Abdul Khodir bahwa

"Tempatnya baik, sewa kamarnya juga tidak terlalu mahal”,

Selain itu Yuant Tiandho juga menyebutkan bahwa :

"Dengan harga yang standar Hotel ini cukup bagus terlebih untuk yang harus menginap karena transit dari bandara Palembang”.

Pelaksanaan komunikasi pemasaran memberikan fungsi penting dalam tujuan pemasaran, beberapa elemen penting dalam proses pemasaran yang memberikan efek besar tercapainya kegiatan pemasaran terdapat dalam unsur Marketing Mix, seperti Product, Price, Place, Promotion, People, Physical Evidence, Process, Packaging, dan Payment. Beberapa elemen 
tersebut memberikan nilai lebih terhadap suatu produk yang bisa ditawarkan kepada pembeli dan biasanya ditampilkan didalam setiap kegiatan pemasaran.

Berikut akan diuraikan data jumlah penginap pada Hotel Best Skip selama 4 tahun yang lalu, yang terus mengalami kemajuan ataupun kemunduran namun pihak Hotel tetap berusaha melakukan strategi yang tepat dan benar agar dapat bersaing dalam dunia bisnis nya. Melalui bagan ini maka bisa dilihat seperti apa hasil yang didapatkan dari strategi komunikasi nya, berikut bagan jumlah pengunjung pada Hotel Best Skip Palembang :

\section{Bagan Jumlah Pengunjung}

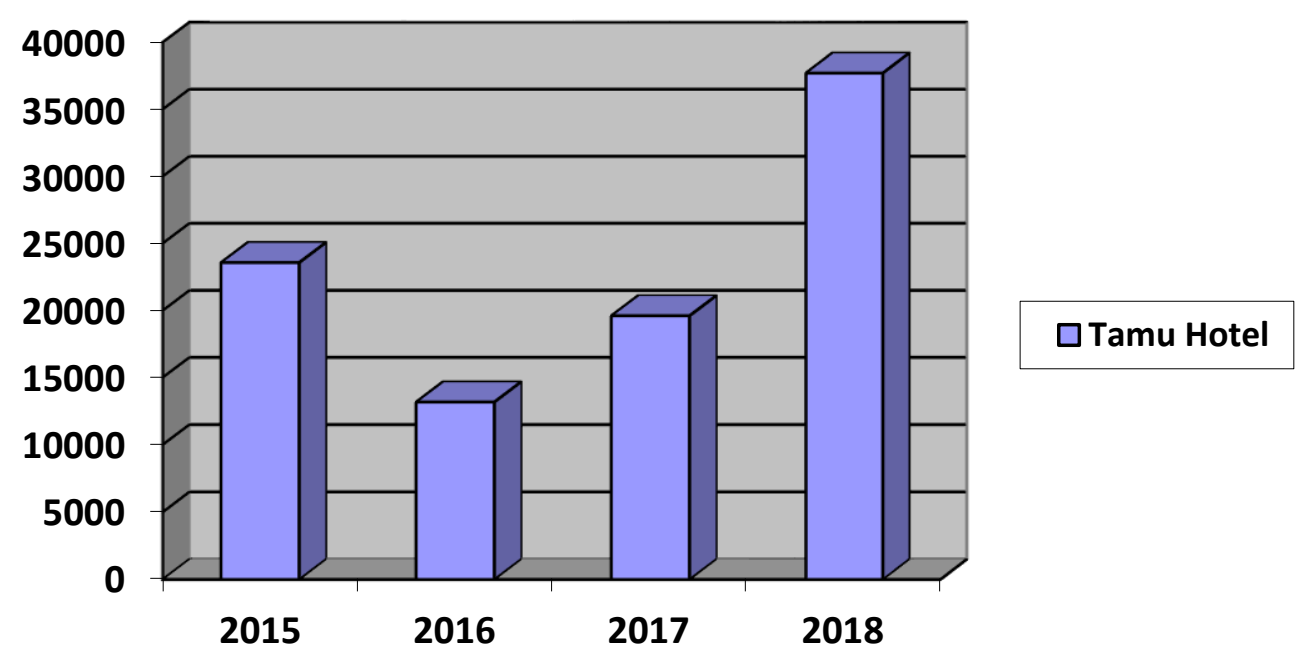

Jumlah tamu yang menginap pada tahun 2015 mencapai 20.000 orang lebih, namun pada tahun 2016 mengalami penurunan dikarenakan banyaknya persaingan dengan munculnya Hotel lain yang ada di Palembang. Namun pada tahun 2017 Hotel ini mengalami perkembangan sehingga semakin meningkatnya jumlah penginapnya, dan pada tahun 2018 jumlah penginap di Hotel ini terus meningkat. Seperti yang diungkapkan oleh Wilza :

"Tamu yang menginap di Hotel ini bermacam-macam, ada yang dari Mancanegara ada juga dari Indonesia. Tapi kebanyakan dari Indonesia, kalo Mancanegara kayak lagi ada ASIAN GAMES tahun ini kita lebih banyak tamu yang menginap disini”.

Selain itu, Hotel ini memiliki beberapa fasilitas yag bisa dinikmati oleh pengunjung dan menjadi salah satu alasan pengunjung untuk menginap disini. Hal ini diungkapkan oleh Dinda :

"Ada beberapa fasilitas yang bisa dinikmati pengunjung, di lobby nya ada karaoke, cyber area, biliar, PS4, dan lain sebagainya. Disini kelebihannya bagi pengunjung yang ingin 
menikmati cyber area nya tidak dikenakan biaya atau gratis, kemudian untuk kareokenya lebih santai hanya menggunakan infocus dan youtube saja atau lebih terbuka, hotel ini bisa dibilang syar'i tapi bukan syar'i, dan untuk spa nya bukan spa yang sembarangan, tapi lebih cenderung kekeluargaan”.

Beberapa fasilitas yang ada di Hotel ini akan memberikan semua kebutuhan tamu dengan pelayanan yang baik agar konsumen dapat menginap senyaman mungkin. Hotel ini memberikan pelayanan kamar 24 jam, Wi-Fi gratis, pusat bisnis 24 jam, receptionist 24 jam, parkir gratis, spa, layanan cuci pakaian 24 jam, 4 meeting room dan 1 ballroom, restoran 24 jam, hotel bebas rokok (No Smoking Area), dan lain sebagainya

Selain itu, komentar pelanggan pada website Hotel Best Skip juga menunjukkan bahwa fasilitas Hotel ini cukup luas seperti yang diungkapkan oleh Londa Bondang bahwa :

"Hotel ini cukup lumayan untuk keluarga yang menginap di Palembang. Parkiran mobil cukup luas dibagian belakang, pada siang hari jalan raya yang cukup dilalui 2 kendaraan roda empat menuju atau kearah sebaliknya menuju pusat kota Palembang lalu lintas cukup ramai”.

Komentar pelanggan lainnya juga menyebutkan bahwa fasilitas di Hotel ini memang memadai seperti yang diungkapkan oleh Arya bahwa :

"Hotel ini banyak permainan seperti PS4, biliar mini, bar kecil, tempat santai sambil ngopi, yang pasti tempatnya sangat nyaman dan pokoknya recomended banget”.

Faktor yang mempengaruhi penginap untuk menginap di Hotel ini yakni dikarenakan mempunyai daya tarif yang murah, fasilitas yang lengkap dan pelayanan yang baik sehingga dapat memenuhi kebutuhan konsumen. Hotel ini lebih mengutamakan kenyamanan pelanggan guna menarik perhatian konsumen atau pelanggan untuk menginap.

\section{KESIMPULAN}

Komunikasi langsung yang dilakukan oleh Hotel ini yaitu berupa Sales Promotion, Personal Selling, dan Direct selling. Sedangkan komunikasi tidak langsung yang dilakukan Hotel ini yaitu dengan menggunakan promosi melalui media sosial sepertifacebook, tweeter, instagram, internet, brosur, dan lain sebagainya. Hotel Best Skip Palembang menerapkan strategi yang lebih fokus kepada kegiatan promosi, namun Hotel ini juga berusaha untuk memaksimalkan kualitas produk, fasilitas, harga dan pelayanannya guna untuk memenuhi kebutuhan pelanggan. Kegiatan promosi pemasaran yang dilakukan oleh Sales Marketing di Hotel Best Skip yaitu melalui spanduk promosi maupun internet, dikarenakan kegiatan promosi ini memakan biaya yang relatif murah namun dapat memiliki hasil yang maksimal. 
Kegiatan internal Hotel setiap hari mengadakan meeting harian untuk melihat bagaimana perkembangan dan kondisi Hotel. Proses srategi yang selanjutnya yaitu dengan melakukan analisis situasi oleh Marketing dan Manager Hotel seperti mengadakan riset dengan menganalisa laporan Income Audit atau pendapatan setiap harinya baik berupa keuangan maupun jumlah tamu yang menginap. Selain itu, pihak Marketing juga memantau Feedback atau respon pelanggan melalui komentar pelanggan pada website Hotel. Faktor yang mempengaruhi penginap di Hotel Best Skip yaitu karena Hotel ini memliki harga yang murah dan fasilitas yang cukup lengkap

Pentingnya membentuk atau menambah tim marketing untuk menunjang kegiatan marketing di Hotel Best Skip Palembang agar lebih mudah melakukan setiap programnya, sehingga dapat menghasilkan keuntungan yang maksimal bagi perkembangan dan kemajuan Hotel. Selain itu, melakukan promosi secara maksimal melalui media sosial dan website Hotel agar minat pelanggan untuk menginap lebih maksimal. 


\section{DAFTAR PUSTAKA}

Arimurti, Ayunda, Strategi Komunikasi Pemasaran Grand Orchid Hotel Surakarta, http://www.jurnalkommas.com/docs/JURNAL\%20ayunda\%20arimurti.pdf. Diakses tanggal 21 September 2018

Laurencya, Regina, Strategi Komunikasi Pemasaran Grand Wahid Hotel Salatiga dalam Upaya Meningkatkan Pelayanan terhadap Konsumen, http://repository.uksw.edu/bitstream/123456789/10390/2/T1_602013605_full\%2520text.p df. Diakses tanggal 21 September 2018

Mefri, Happy Pengaruh Kualitas Pelayanan Karyawan Front Office Terhadap Kepuasan Tamu Menginap di Hotel The Axana Padang, http://media.neliti.com/media/publications/72334ID-pengaruh-kualitas-pelayanan-karyawan-pro.pdf. Diakses tanggal 11 Oktober 2018

Morissan. (2010). Komunikasi Pemasaran Terpadu, Jakarta : Prenadamedia Group, Edisi I.

Permana Budi, Agung. (2013). Manajemen Marketing Perhotelan, Yogyakarta : CV Andi Offset, Edisi 1

Soraya, Warda, Strategi External Relation Hotel Novotel Palembang dalam Meningkatkan Citra Perusahaan,http://eprints.radenfatah.ac.id/1333/1/Warda\%20Soraya\%20\%28510074\%29. pdf. Diakses tanggal 11 Oktober 2018

Wijayanto, Kenmada, et al. (2013). Perencanaan Komunikasi Bisnis dalam Perencanaan Komunikasi, Bandung: Ultimus, Cetakan 1, 